\title{
Determination of Allura Red and Tartrazine in Food Samples by Sequential Injection Analysis Combined with Voltammetric Detection at Antimony Film Electrode
}

\author{
J. A. Rodríguez, ${ }^{*[a]}$ M. G. Juárez, ${ }^{[a]}$ C. A. Galán-Vidal, ${ }^{[a]}$ J. M. Miranda, ${ }^{[b]}$ and E. Barrado ${ }^{[c]}$
}

\begin{abstract}
An antimony film electrode prepared on-line and installed as part of a sequential injection system, was used as an electrochemical detector to determine azo dyes in food samples. The influence of several flow variables were evaluated using a central composite design. In optimal conditions, the linear range of the calibration
\end{abstract}

curve varied from $1-5 \mu \mathrm{M}$, with a limit of detection limit of $0.3 \mu \mathrm{M}$. The relative standard deviation of analytical repeatability was $<5.0 \%$. The method was validated by comparing the results obtained with those provided by
HPLC; no significant difference were seen.

Keywords: SIA • Voltammetry • Antimony film electrode $\cdot$ Allura red · Tartrazine

\section{Introduction}

Natural and synthetic dyes are added to food and beverages to improve the visual appearance of the final products. Synthetic dyes are commonly used because of their lower cost and higher stability toward light, oxygen and $\mathrm{pH}$ changes [1]. Allura red (AR) and Tartrazine (T) are two azo dyes commonly that can be found in common food products. However, they can cause allergic and intolerance reactions [2]. The Food and Drug Administration establish acceptable daily intakes of 7 and $5 \mathrm{mg} / \mathrm{kg} /$ day for $\mathrm{AR}$ and $\mathrm{T}$, respectively [3]. In Mexico, the maximum limits in drinks are $300 \mathrm{mg} \mathrm{L}^{-1}$ for $\mathrm{AR}$ and $100 \mathrm{mg} \mathrm{L}^{-1}$ for $\mathrm{T}$, individually and $100 \mathrm{mg} \mathrm{L}^{-1}$ as mixture [4].

Azo dyes have high values of molar absorption coefficients, thus spectrophotometry has been commonly applied to determine these compounds [5-7]. Other methods described for this purpose are high performance liquid chromatography [8], capillary electrophoresis [9] and electrochemical techniques. Cathodic voltammetry has been applied to determine azo dyes as a consequence of the reduction process obtained using mercury [10], modified carbon [11-12] and bismuth film electrodes [13]. The antimony film electrode (SbFE) has demonstrated to possess adequate analytical performance compares to bismuth and mercury films during analysis of inorganic ions by anodic stripping voltammetry [14]. Regarding the analysis of azo compounds by SbFE, it has been described the analysis of sulfasalazine in pharmaceutical formulation [15].

Nowadays a laboratory should be able to perform determinations of a large number of samples in an accurate, reproducible, fast and economic way. Flow techniques and in particular Sequential Injection Analysis (SIA) has become is becoming an important tool for the automation of chemical procedures [16]. The combination of SIA with voltammetric detection improves the sensitivity and reproducibility of the method as a consequence of the highly controllable conditions provided by the flowing solutions. The use of an eight port selection valve in SIA allows sample conditioning before the measuring step, as well as the use of standard addition technique commonly used in electroanalytical methods [17]. The present work describes the development of a methodology to determine allura red and tartrazine in food samples using a SIA system with voltammetric detection at SbFE.

\section{Experimental}

\subsection{Reagents and Chemicals}

All solutions were prepared by dissolving the respective analytical grade reagent in deionized water with a resistivity not less than $18.0 \mathrm{M} \Omega \mathrm{cm}$, provided by a Milli-Q system (Millipore, Bedford, MA, USA). Sodium hydroxide, acetic acid, phosphoric acid and boric acid were obtained from J. T. Baker (Phillipsburg, NJ, USA). A

[a] J. A. Rodríguez, M. G. Juárez, C. A. Galán-Vidal Área Académica de Química, Universidad Autónoma del Estado de Hidalgo

Carr. Pachuca-Tulancingo Km. 4.5, 42184, Mineral de la Reforma, Hgo, Mexico

*e-mail: josear@uaeh.edu.mx

[b] J. M. Miranda

Dpto. Química Analítica, Nutrición y Bromatología, Facultad de Veterinaria, Universidad de Santiago de Compostela

Pabellón 4 planta baja, Campus Universitario s/n, 27002, Lugo, Spain

[c] E. Barrado

Departamento de Química Analítica, Universidad de Valladolid

Campus Miguel Delibes, Paseo de Belén 7, 47011 Valladolid, Spain 
$50 \mathrm{mgL}^{-1} \mathrm{Sb}$ (III) solution was prepared by dilution of $1.0 \mathrm{~g} \mathrm{~L}^{-1}$ standard solution of $\mathrm{Sb}$ (III) (Hycel, Atomic spectroscopy standard, Mexico) in acetate buffer solution $(\mathrm{pH} 4.0,1.0 \mathrm{M})$. Working standard solutions of AR and T (Sigma Aldrich, St. Louis, MO, USA) were prepared monthly from a $0.01 \mathrm{M}$ stock solution, by dilution with the acetate buffer solution. Working solutions $(3-30 \mu \mathrm{M})$ of acesulfame K, albumin from chicken egg, aspartame, casein from bovine milk, sodium citrate, glucose and sucralose (all from Sigma Aldrich) were prepared by dissolution of adequate amounts of the pure compounds in acetate buffer solution.

A total of 10 samples (liquid and solid) were bought from different supermarkets in Pachuca de Soto (Hidalgo, Mexico). Candies and gelatin powder $(1.0 \mathrm{~g})$ or corn flour based and isotonic drink samples $(5 \mathrm{~mL})$, were mixed with $20 \mathrm{~mL}$ of $\mathrm{HCl}(0.1 \mathrm{M})$ in an ultrasonic bath for $3 \mathrm{~min}$; this suspension was filtered through a $0.45 \mu \mathrm{m}$ membrane filter and diluted with water in a $25 \mathrm{ml}$ calibration flask. These solutions were frozen $\left(-21^{\circ} \mathrm{C}\right)$ until analysis.

\subsection{Sequential Injection Analysis with Voltammetric Detection}

The SIA-VD (Figure 1) consists of a burette multisyringe with programmable speed (Sy, microBu 2030, Crison) used to aspire and dispense the reagent solutions, an eight-way selection valve (V, Crison) and a bipotentiostat (D, Drop Sens $\mu$ STAT 200, Spain) with a wall jet electrochemical cell for screen printed carbon electrodes (Drop Sens 100A, Spain) was used as detector. All of the tubing used to connect the different components of the flow system was $0.8 \mathrm{~mm}$ (i.d. Omnifit PTFE). the instrumental devices were controlled by Autoanalysis 5.0 software (Sciware, Spain).

The analytical cycle began with the aspiration of $\mathrm{Sb}$ (III) solution ( $\mathrm{Sb}, 100 \mu \mathrm{L}, 50 \mathrm{mgL}^{-1}$ ) into the loading reactor $\left(R_{1}, 100 \mathrm{~cm}\right)$ at a flow rate of $30 \mathrm{mLmin}^{-1}$. This solution was then directed towards the detector where the SbFE was formed by applying a potential of $-1.0 \mathrm{~V}$ for $60 \mathrm{~s}$ at a flow rate of $0.5 \mathrm{~mL} \mathrm{~min}{ }^{-1}$. The electrode surface was potentiostatically cleaned at $+0.2 \mathrm{~V}(30 \mathrm{~s})$ in flowing supporting electrolyte after 4 injections. These steps were repeated to renew surface of the SbFE.

Once formed the SbFE, the sample was aspired using a binary strategy consisting on the intercalation of sample (S) segments of $30 \mu \mathrm{L}$ with standard solution $\left(\mathrm{SS}_{1-3}\right)$ segments of $30 \mu \mathrm{l}$. The total aspired volume was $120 \mu \mathrm{L}$ of $\mathrm{S}$ and $120 \mu \mathrm{L}$ of SS. The binary sampling strategy creates multiple reaction interfaces which contribute a faster sample homogenization [16]. The mixture was completed in a reaction coil $\left(R_{2}, 20 \mathrm{~cm}\right)$ whilst it was propelled to the detector at a flow rate of $1.2 \mathrm{mLmin}^{-1}$ during $20 \mathrm{~s}$. Then the flow was stopped and a cathodic scan was applied from 0.0 to $-1.0 \mathrm{~V}$ in the differential pulse mode (DPV). The following DPV parameters were applied: pulse amplitude, $50 \mathrm{mV}$; step potential, $10 \mathrm{mV}$; and modulation time, $1 \mathrm{~ms}$.

\subsection{High Performance Liquid Chromatography}

The concentration of $\mathrm{AR}$ and $\mathrm{T}$ in the samples was also determined for comparative purposes using high performance liquid chromatography with UV detection. The apparatus used was an Agilent Infinity 12060 (Agilent technologies, Santa Clara, CA, USA) equipped with a diode array detector and a manual injector connected to a $25 \mu \mathrm{L}$ external loop. Chromatographic separation was achieves with a C18 zorbax column $(5 \mu \mathrm{m} ; 150 \mathrm{~mm} \times$ $4.6 \mathrm{~mm}$ i.d.) (Agilent technologies). The mobile phases used for HPLC experiments consisted of two solutions, one a solution of methanol (Taufkirchen, Germany), and the second a solution of $0.1 \%(\mathrm{v} / \mathrm{v})$ trifluoroacetic acid at pH 4.4 adjusted with triethylamine. Separation was performed using a mobile phase gradient: $0-1 \mathrm{~min}, 17 \% \mathrm{~B}$,

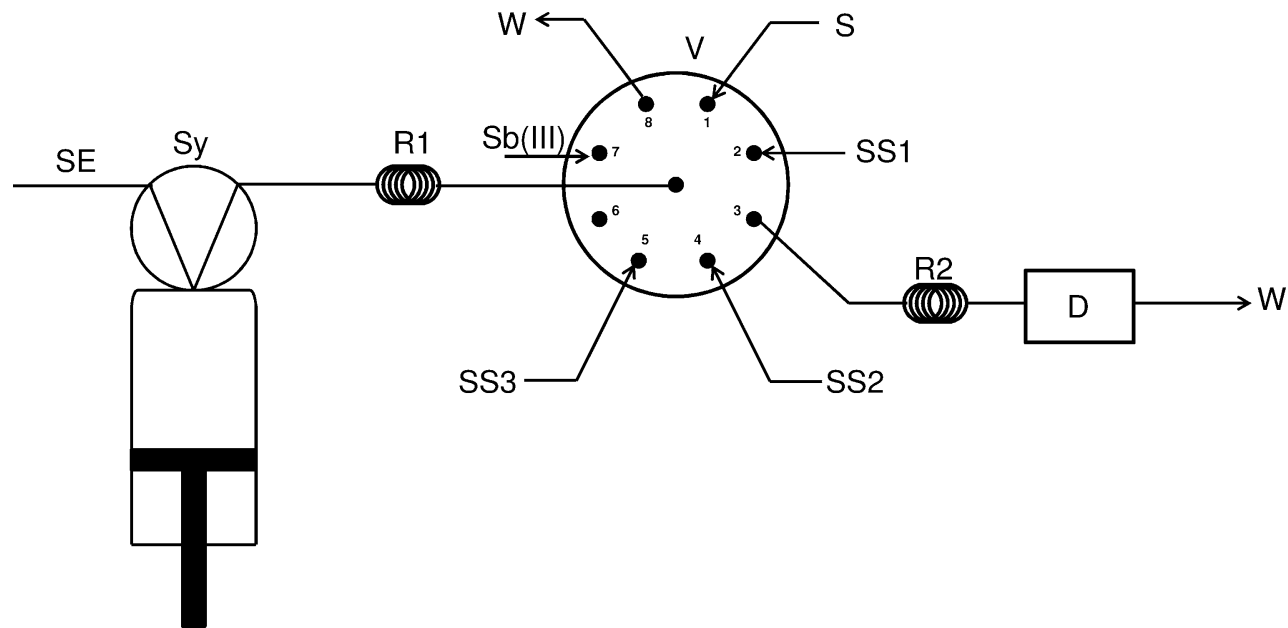

Fig. 1. Sequential Injection system proposed to determine azo dyes. Sy, syringe; SE, supporting electrolyte (acetate buffer solution, $\mathrm{pH} 4.0,1.0 \mathrm{M}) ; R_{1}$, loading reactor; $V$, selection valve; $\mathrm{Sb}(\mathrm{III})$, antimony solution $\left(50 \mathrm{mg} \mathrm{L}^{-1}\right)$; $\mathrm{S} 1-3$, standard solutions; $\mathrm{S}$, sample; $R_{2}$, mixing reactor; $\mathrm{D}$, wall jet electrochemical detector; $\mathrm{W}$, waste. 
1-12 min, $17-100 \%$ B, $12-13$ min $100-17 \%$ B, $13-18$ min, $17 \% \mathrm{~B}$. The flow rate was kept constant at $1.0 \mathrm{~mL} \mathrm{~min}^{-1}$ during the separation. The chromatogram was monitored at $254 \mathrm{~nm}$.

\section{Results and Discussion}

\subsection{Optimization of the SIA-VD System}

$\mathrm{AR}$ and $\mathrm{T}$ have cathodic responses at glassy carbon electrodes [12] and BiFE [13]. The electrochemical reduction of azo dyes at SbFE was evaluated initially using DPV in the $\mathrm{pH}$ range from $4.0-8.0$, as shown in Figure 2. A $3.0 \mu \mathrm{M}$ solution of each analyte in Britton-Robbinson buffer solution (BR, $0.01 \mathrm{M}$ of each acid) was aspired and propelled by the carrier solution (BR) to the detector to
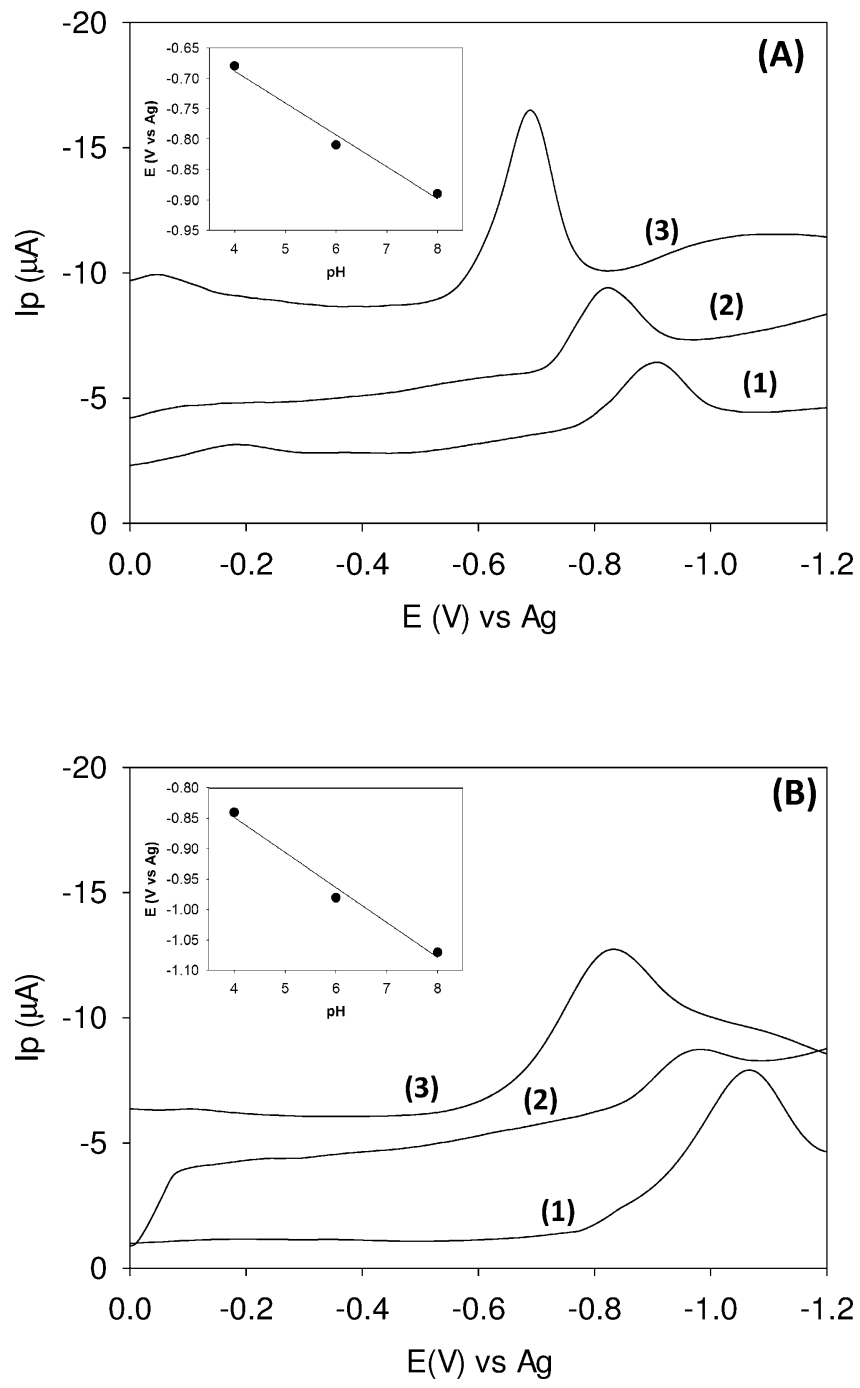

Fig. 2. Differential pulse voltammograms of $3 \mu \mathrm{M}$ azo dyes solutions obtained at SbFE in Britton-Robinson buffer solutions with pH 4.0 (1), 6.0 (2), and 8.0 (3). DPV settings pulse amplitude, $50 \mathrm{mV}$; step potential, $10 \mathrm{mV}$; and modulation time, $1 \mathrm{~ms}$. Inset: Dependence of peak potential upon the $\mathrm{pH}$ of measurements solution. perform the voltammetry. A signal for reduction of $\mathrm{T}$ (Figure 2A) and AR (Figure 2B), with a clear dependence on $\mathrm{pH}$ on signal peak potential $\left(E_{\mathrm{p}}\right)$, was obtained. The Ep was shift towards more negative values with the increment of the $\mathrm{pH}$ value. A linear relationship with slopes values of -0.057 and $-0.053 \mathrm{~V} \mathrm{pH}^{-1}$ were obtained for $\mathrm{T}$ and $\mathrm{AR}$, respectively. These values indicate an equal number of electrons and $\mathrm{H}^{+}$in the reaction, which is congruent with the reduction of the azo group $(-\mathrm{N}=\mathrm{N}-)$ to hydrazo species (-NH-NH-) $[13,15]$. In addition, the highest signal for $\mathrm{AR}$ was observed at $\mathrm{pH} 4.0$; this $\mathrm{pH}$ value allows determine $\mathrm{T}$ at less cathodic. A $\mathrm{pH}$ of 4.0 (acetate buffer solution) was therefore selected for subsequent analysis.

Once evaluated the effect of the $\mathrm{pH}$ value, a central composite design was used for the study of the instrumental flow variables. In flow systems, the most critical variables were [18]: the flow rate $(Q)$ which controls the dispersion and the sample rate of the methodology; the injection volume $(V)$ is related with the concentration of the analyte in the electrochemical cell; and the reaction coil length $\left(R_{2}\right)$ which is useful to ensure adequate dispersion of the sample and the carrier solution. The output variable was the peak height $\left(I_{\mathrm{p}}, \mu \mathrm{A}\right)$ obtained from the analysis of a $\mathrm{T}$ solution $(3.0 \mu \mathrm{M})$ prepared in acetate buffer solution (1.0 M, pH 4.0).

The response surface was mapped and explored using a rotatable three-factor central composite design, with five levels of each factor $(\alpha=1.68)$. The experimental matrix used during optimization is shown in Table 1. All experiments were carried out randomly.

A statically significant linear model accounting for $84 \%$ of the variance fitted to the data. The response surface fitted to the following equation (linear model)

Table 1. Design matrix and responses for the central composite design.

\begin{tabular}{lclr}
\hline $\begin{array}{l}\text { Flow rate }(Q, \mathrm{~mL} \\
\left.\mathrm{min}^{-1}\right)\end{array}$ & $\begin{array}{l}\text { Injection volume } \\
(V, \mu \mathrm{L})\end{array}$ & $\begin{array}{l}\text { Reactor length } \\
\left(R_{2}, \mathrm{~cm}\right)\end{array}$ & $\begin{array}{l}I_{\mathrm{p}} \\
(\mu \mathrm{A})\end{array}$ \\
\hline 0.50 & 50 & 30 & 1.2 \\
1.00 & 50 & 30 & 2.2 \\
0.50 & 100 & 30 & 9.2 \\
1.00 & 100 & 30 & 16.8 \\
0.50 & 50 & 60 & 2.8 \\
1.00 & 50 & 60 & 0.8 \\
0.50 & 100 & 60 & 5.6 \\
1.00 & 100 & 60 & 8.8 \\
0.33 & 75 & 45 & 4.9 \\
1.17 & 75 & 45 & 7.3 \\
0.75 & 33 & 45 & 0.9 \\
0.75 & 117 & 45 & 13.4 \\
0.75 & 75 & 20 & 7.7 \\
0.75 & 75 & 70 & 2.9 \\
0.75 & 75 & 45 & 5.9 \\
0.75 & 75 & 45 & 6.2 \\
0.75 & 75 & 45 & 5.5 \\
0.75 & 75 & 45 & 6.3 \\
0.75 & 75 & 45 & 6.2 \\
0.75 & 75 & 45 & 5.5 \\
\hline
\end{tabular}




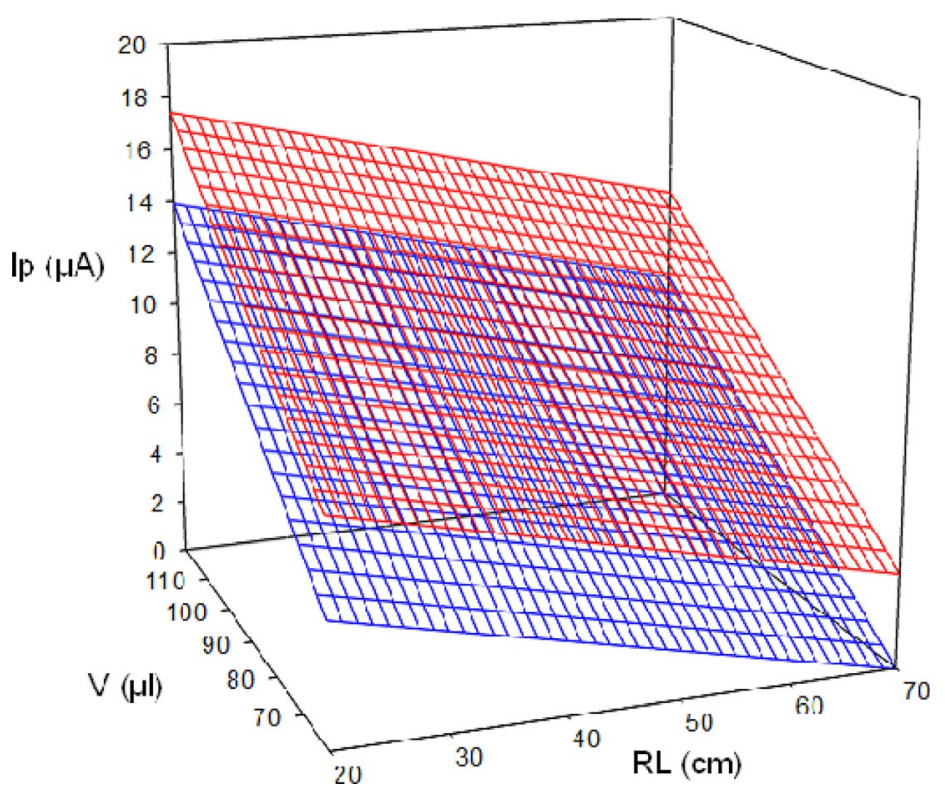

Fig. 3. Optimal response surfaces (as peak height, $\mu \mathrm{A}$ ) at flow rates of 0.33 (blue) and 1.2 (red) $\mathrm{mL} \mathrm{min}^{-1}$.

$I_{\mathrm{p}}=-4.7618+4.05256 Q+0.1594(V)-0.0951\left(R_{2}\right)$

Analysis of variance of the results shows that the three variables evaluated have a statistically significant effect on the $I_{\mathrm{p}}$ value $(p<0.05)$. Analysis of the residuals from the regression model and the lack of fit test revealed that the linear model could be an adequate surface over the experimental interval studied.

The response surfaces obtained at fixed flow rates of 0.33 and $1.2 \mathrm{~mL} \mathrm{~min}^{-1}$ are shown in Figure 3. It is clear that $I_{\mathrm{p}}$ of the signal increases with the injection volume and the flow rate. In contrast, the results indicate that decreasing the reaction coil length causes a significant increase in peak height. This behavior is attributed to the binary sampling strategy applied, in which the combination of higher number of sample segments with higher flow rates allows the use of shorter reaction coils in order to prepare the sample for analysis $[16,19]$. The combination selected as optimum was: flow rate, $1.2 \mathrm{~mL} \mathrm{~min}^{-1}$; injection volume, $117 \mu \mathrm{L}$ and reaction coil length, $20 \mathrm{~cm}$. Under these conditions a predicted signal of $17.4 \mu \mathrm{A}$ was expected which is close to the experimental value obtained $16.9 \mu \mathrm{A}$.

\subsection{Analytical Properties of the Procedure}

The calibration plots for AR and Tobtained in the optimized experimental conditions are shown in Figure 4. Three replicate measurements of each standard were made and the mean values were used for calculations. A lineal dependence of the peak height with the dye concentration was found in the range $1.0-5.0 \mu \mathrm{M}$ with limits of detection of 0.3 for both analytes. The limits of detection were calculated according to the IUPAC criteria, i.e.
3.0 times the value of $s_{\mathrm{e}} / b_{1}$, were $s_{\mathrm{e}}$ is the square root of the residual variance of the standard curve and $b_{1}$ is the analytical sensitivity [20]

The intermediate precision of the procedure, expressed as the relative standard deviation for three determinations made on different electrodes on a $3.0 \mu \mathrm{M}$ standard solution of AR and T were 2.6 and $2.9 \%$, respectively. The repeatability of the voltammetric signal was below $5 \% R S D$ for all standard solutions and samples. The useful life of the SbFE was evaluated through the continuous analysis of a $3.0 \mu \mathrm{M} \mathrm{T}$ under optimal conditions. After 10 analyses, the peak height value showed good repeatability; the $R S D$ was $4.1 \%$.

Under optimal conditions, 5 analytical cycles per hour can be carried out. AR and $\mathrm{T}$ were quantified in food samples by the standard additions method using three additions and two replicated measurements after each standard addition. In these conditions, the total analysis time per sample was around $15 \mathrm{~min}$. Once completed the full analytical cycle, a new SbFE was renewed on-line in order to prevent passivation of the electrode.

The effect of the sample constituents (acesulfame K, albumin from chicken egg, aspartame, casein from bovine milk, sodium citrate, glucose and sucralose) present in the food samples extracts was studied. Solutions containing $3.0 \mu \mathrm{M}$ of both AR $\left(1.5 \mathrm{mg} \mathrm{L}^{-1}\right)$ and $\mathrm{T}\left(1.6 \mathrm{mg} \mathrm{L}^{-1}\right)$ and the potentially interfering element at higher concentrations (interfering compound/dye ratio assayed, 10:1 concentrations in $\mathrm{mgL}^{-1}$ ) were analyzed. The added element was considered to interfere when it caused a variation in the stripping signal greater than or equal to $\pm 5 \%$ compared to the response obtained in its absence. The results showed that none of the compounds interfered in the determination of the dyes. Proteins are a potentially inter- 

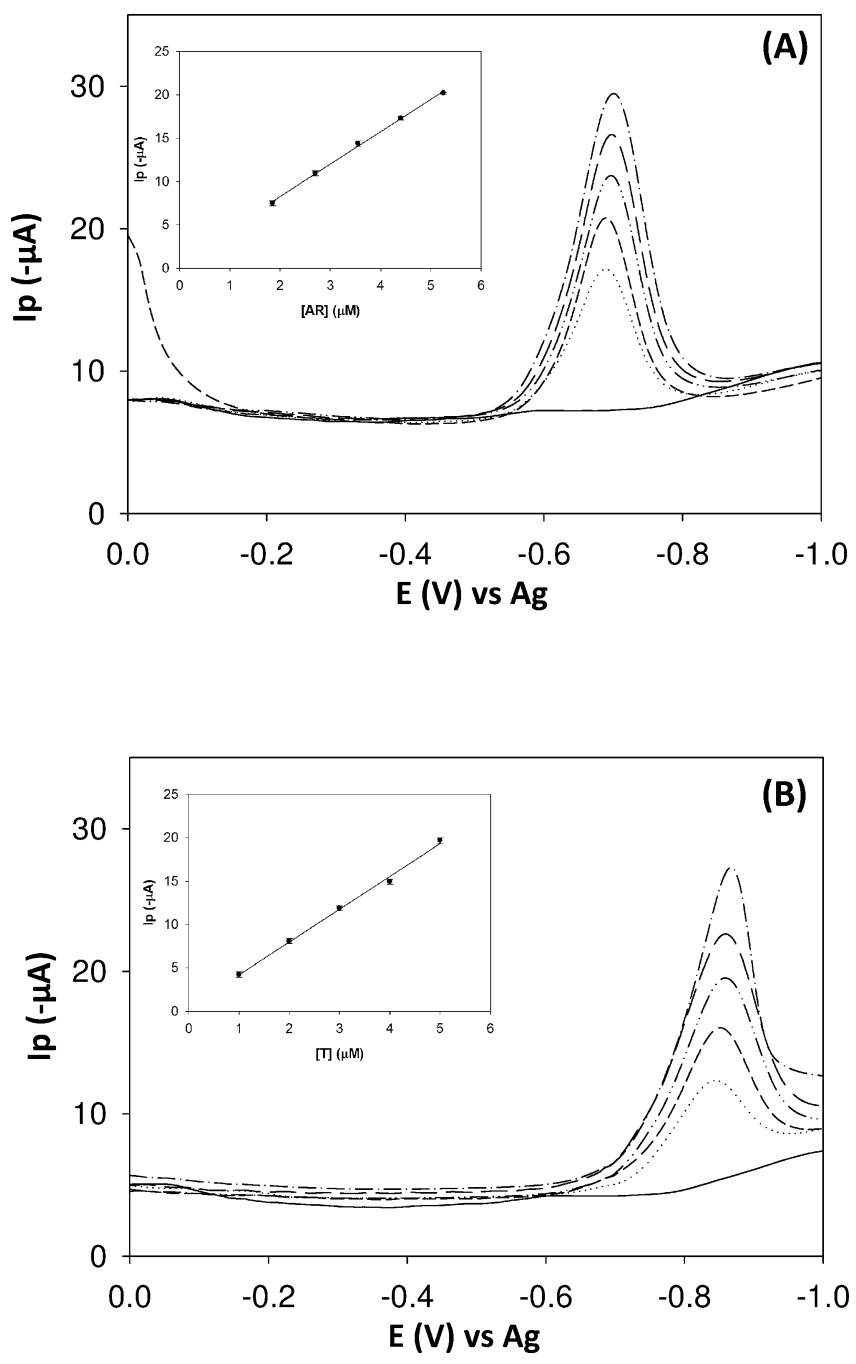

Fig. 4. Voltammetric measurements of allura red (A) and tartrazine (B) solutions for increasing dye concentrations from 1.0 to $5.0 \mu \mathrm{M}$ in acetate buffer solution $(\mathrm{pH} 4.0)$ together with the background response at SbFE. Inset show the calibration plot obtained using the pure dyes. DPV setting are as Fig. 2

fering in the signal, but the $\mathrm{pH}$ selected for sample treatment and determination are below their isoelectric point. The sample was then filtered before its injection into the SI system minimizing then the inference of these compounds.
The proposed method was used to determine both dyes in food samples. Table 2 shows the results obtained. In order to validate the results, the concentration of dyes in the extracts was also determined by HPLC. The results obtained by both methods were compared using a paired t-test. The values of calculated $t$ were then compared to a critical value for 26 degrees of freedom at the $95 \%$ confidence level $(t=2.78)$. No significant differences were seen between the results obtained with each method.

\section{Conclusions}

The utility of the combination of sequential injection analysis with voltammetry detection at SbFE electrodes during azo dyes analysis in food samples has been demonstrated. The SIA-VD system developed has good characteristics for routine with adequate figures of merit. The SbFE could be easily renewed on-line without affecting the analytical parameters. This feature represents a significant advantage over traditional electrodes since no polishing procedures are required. The proposed methodology based on SIA and DPV, is automated, economic, with high determination rate, provided determinations comparable to those obtained by HPLC reference method.

\section{Acknowledgements}

The authors wish to thank the CONACyT (Project INFR2014-227999), Junta de Castilla y Leon, (Project VA171U14) and Consejería de Cultura, Educación e Ordenacion Universitaria, Xunta de Galicia (Project EM2012/ 153).

\section{References}

[1] S. Damodaran, K. L. Parkin, O. R. Fennema, Food chemistry, $2^{\text {nd }}$ ed., CRC Press, Boca Raton, FA, 2007.

[2] L. E. Arnold, N. Lofthouse, E. Hurt, Neurotherapeutics 2012, 9, 599-609.

[3] FDA/CFSAN Food Advisory Committee, Center for Food Safety and Applied Nutrition, March 30-31, 2011, Food Advisory Committee Meeting.

[4] Norma Oficial Mexicana NOM-218-SSA1-2011.

Table 2. Contents (mean and $R S D \%, n=3$ ) of allura red and tartrazine determined in food samples by the proposed SIA-DPV system, and comparison between concentrations determined by HPLC. Concentration units $\mathrm{mg} \mathrm{kg}^{-1}$ and [a] $\mathrm{mgL}^{-1}$.

\begin{tabular}{lllll}
\hline Sample & Dye & SI-DPV & HPLC & $t_{\text {calc }}$ \\
\hline Flavored cornflour & AR & $22.3(1.8)$ & $23.2(4.1)$ & 1.45 \\
Tomato bouillon cube & & $11.7(1.5)$ & $12.1(3.5)$ & 1.41 \\
Candy & & $135.1(1.7)$ & $133.1(3.4)$ & 0.68 \\
Gelatin powder & & $45.9(1.3)$ & $46.2(1.3)$ & 0.75 \\
Isotonic drink [a] & $\mathrm{T}$ & $6.3(3.3)$ & $6.5(4.2)$ & 0.51 \\
Juice powder & & $227.4(2.1)$ & $226.9(1.7)$ & 0.14 \\
Gelatin powder & & $40.5(2.2)$ & $41.6(4.3)$ & 0.93 \\
Bouillon cube & & $62.3(2.2)$ & $59.8(4.4)$ & 1.49 \\
Candy & $172.0(1.5)$ & $172.9(4.9)$ & 0.18 \\
Isotonic drink [a] & $15.1(2.8)$ & $15.7(4.8)$ & 1.34 \\
\hline
\end{tabular}


[5] H. M. Pinheiro, E. Touraud, O. Thomas, Dyes Pigments 2004, 61 121-139.

[6] M. Soylak, Y. E. Unsal, M. Tuzen, Food Chem. Toxicol. 2011, 49, 1183-1187.

[7] M. H. Sorouraddin, A. Rostami, M. Saadati, Food Chem. 2011, 127, 308-313.

[8] J. Kirschbaum, C. Krause, S. Pfalzgraf, H. Bruckner, Chromatographia 2003, 57, S115-S119.

[9] M. Perez-Urquiza, J. L. Beltran, J. Chromatogr. A 2000, 898, 271-275.

[10] R. Gulaboski, C. M. Pereira in Handbook of Food Analysis Instruments, 1st ed., (Ed. S. Otles), CRC Press, Boca Raton, 2008, pp. 390.

[11] M. Chao, X. Ma, Food Anal. Meth. 2015, 8, 130-138.

[12] M. L. S. Silva, M. B.Q. Garcia, J. L. F. C. Lima, E. Barrado, Talanta 2007, 72, 282-288.

[13] B. Claux, O. Vittori, Electroanalysis 2007, 19, 2243-2246.

[14] S. B. Hocevar, I. Svancara, B. Ogorevc, K. Vytras , Anal. Chem. 2007, 79, 8639-8643.
[15] B. Nigovic, S. B. Hocevar, Electrochim. Acta 2011, 58, $523-$ 527.

[16] R. Perez-Olmos, J. C. Soto, N. Zarate, A. N. Araujo, M. C. B. S.M. Montenegro, Anal. Chim. Acta 2005, 554, 116.

[17] L. B. O. dos Santos, C. M. C. Infante, J. C. Masini, Anal. Bioanal. Chem. 2011, 396, 1897-1903.

[18] C. R. T. Tarley, G. Silveira, W. N. L. Santos, G. D. Matos, E. G. P. Silva, M. A. Bezerra, M. Miró, S. L. C. Ferreira, Microchem. J. 2009, 92, 58-67.

[19] J. A. Vieira, I. M. Raimundo, B. F. Reis, E. A. Zagatto, J. L. F. C. Lima, Anal. Chim. Acta 1998, 366, 257-262.

[20] J. Mocak, A. M. Bond, S. Mitchell, G. Scollary, Pure Appl. Chem. 1997, 69, 297-328.

Received: April 29, 2015

Accepted: May 19, 2015 Published online: June 30, 2015 